\title{
Research on the Intelligent Park and Ride System Combined with Public Bicycle
}

\author{
Yalin Liang, Chaoyang Zhang, Su Gao, Shuangshuang Pang, and Zehua Du
}

\begin{abstract}
Nowadays, the volume of private car ownership has increased rapidly, however the car owners cannot get imperfect parking information when they travel, which leads to the phenomenon that parking lots of some regions are full or nearly full while those of the others are nearly empty and the traffic congestion of downtown are increasingly serious. In view of the above problems, this paper puts forward a method of using Internet of things to combine intelligent parking service platform with public bicycle system, so as to realize an intelligent park and rid system by which people can query the information on parking lots and the number of available bicycles and also book and complete the payment at any time. Based on object oriented spatial data model, the system builds a dynamic urban traffic database system based on Oracle database and filters parking lot information automatically following the principle "the distance first and available tools for ride second" to provide the most suitable park and ride mode for travelers.
\end{abstract}

Keywords - Internet of Things, ride system, intelligent parking service platform, public bicycle system.

\section{INTRODUCTION}

According to data released by Traffic Police Bureau of the Ministry of Public Security, until the end of 2015, the volume of motor vehicles in our country has reached 279 million. As a considerable increase in the volume of private car ownership, parking problems have become a big "denunciation" when people travel. In response to the parking problems, corresponding measures have been taken to alleviate the situation both at home and abroad. To solve parking problems, foreign countries have adopted the policies like substantial investment in the construction of parking lots, restriction on private car use, and charging for the vehicles which enter CBD during the peak period, while our country have taken the measures like adding underground parking lots, constructing three-dimensional mechanical garage, encouraging public transport and park and ride system ( $\mathrm{P} \& \mathrm{R})$, and applying parking guidance system to realize parking information to alleviate this problem ${ }^{[1-6]}$. However, due to that the addition of parking lots needs lots of manpower and material and financial resources, that the location and limitations of traditional P\& R facility are too large and other factors, the implementation of many measures have not achieved the desired results. The

traffic problem solution experience of the countries which are advanced in traffic science and technology in the world shows

Yalin Liang, Undergraduate Student, Shandong University of Science and Technology, China. that in order to solve the problem of "parking problems", it must speed up the traffic infrastructure construction and at the same time increase the rate of utilization of the facilities and improve their level of modern management ${ }^{[7-9]}$. Based on this, this paper puts forward an intelligent park and ride system which combines intelligent parking service platform with public transport system by using Internet of things. The system incorporates the bicycle system into the field of intelligent parking and ride and combines the public transport and parking reservation and guidance system, in line with the development of public transport, green transport, and low carbon travel concept.

\section{INTELLIGENT PARK AND RIDE}

\subsection{Intelligent Parking Service Platform.}

Now the available intelligent parking service platform is generally arranged in the vehicle GPS navigation system, or a hand-held mobile terminal. The system based on the technology of Internet of things conducts an intelligent management on the parking spaces in different areas and realizes the collection, release, query, booking and other functions of parking information. Intelligent parking service platform realizes parking guidance, intelligent parking, intelligent billing and platform services in the form of WebServise, and builds an integrated traffic intelligent management program with dynamic and static feature ${ }^{[10-13]}$.

\subsection{Public Bicycle System.}

According to the current situation of our country, there are two kinds of public bicycle service points, fixed and mobile, including bus stop points, residence points, co-construction points, leisure tourism points and university and college points. The points are set based on traffic ride, mainly in the transfer stations of subways, light rails and BRT. The layout size and density of bicycle stations directly affect the utilization of bicycles ${ }^{[7-9]}$. Intelligent park and ride system incorporates public bicycle system into intelligent parking service platform, sets public bicycle station in each parking lots, and carries out real-time information collection, processing and distribution on bicycle system, which is convenient for the car owners to ride the bike after stopping their cars, and also the number of available bicycles can be shown on the information screen of the parking lots queried by the users for users to book.

\subsection{Classification of Parking Lots.}

According to the "one, three, five" travel mode (for less than $1 \mathrm{~km}$ walk, for $1-3 \mathrm{~km}$ ride bicycle, and for 3-5 km take bus or subway), the parking lots are divided into two categories: parking lots which are less than or equal to 1000 meters from 
the search destination, that is to say, starting from which the car owners need not ride a bicycle but walk to the destination after parking are first-level parking lot; those which are $1000 \sim 3000$ meters from the search destination, namely starting from which the car owners need ride a bicycle to reach the destination are second-level parking lots.

\subsection{Realization of Intelligent Park and Ride}

(1) The car owners can use the intelligent park and ride system to query and book the parking spaces by hand-held terminals or vehicle terminals. The car owners only need to input the destination to query, and the system will select from the parking lots surrounding the destination based on the principle "distance first and available bicycles for ride second" to provide the car owners with the most suitable plan for parking. (Detailed ride process is shown in Fig.1 and Fig. 2).

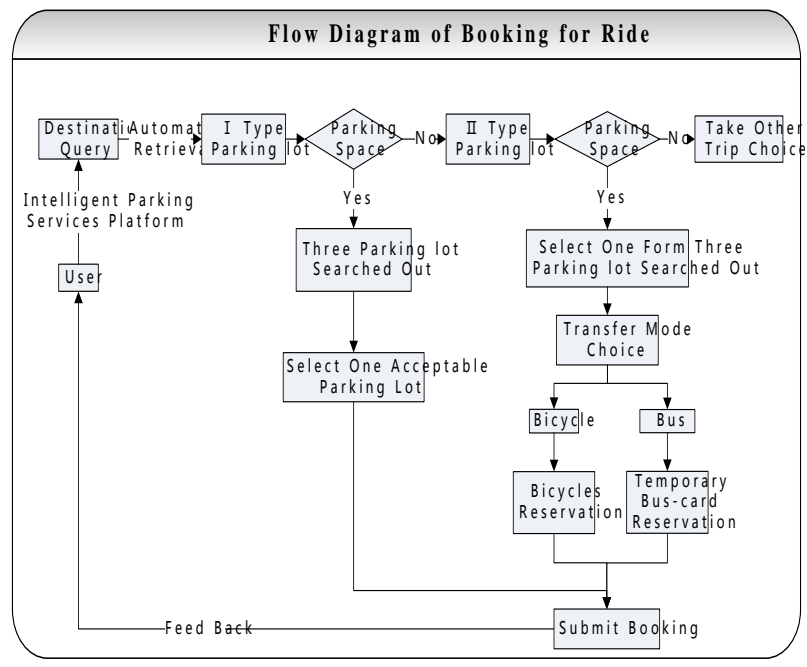

Fig.1 Flow diagram of booking for ride

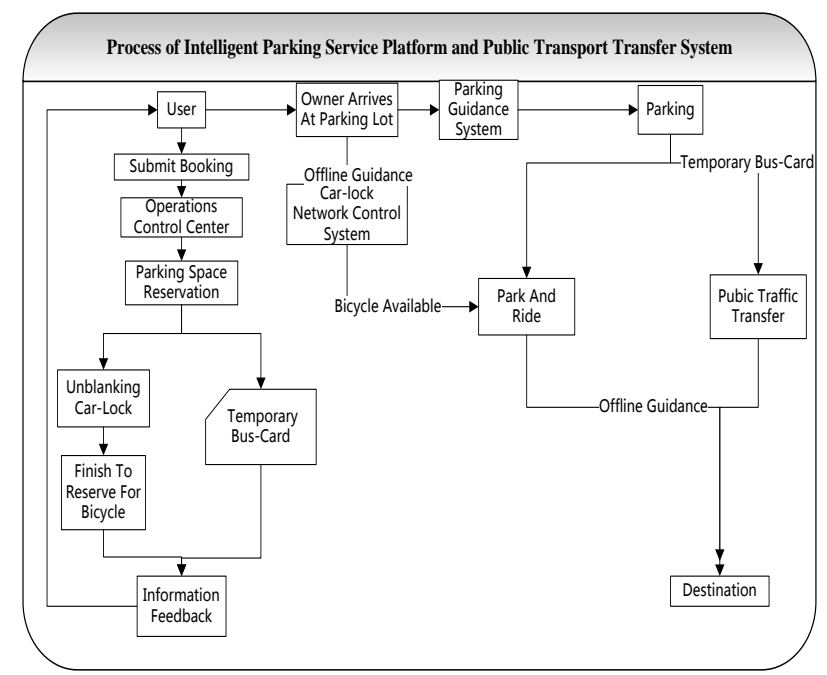

Fig.2 Process of intelligent parking service platform and public transport transfer system

(2) After Parking and Riding A Bicycle. The LCD screen in the front of the bicycle will show the best cycling route, so that the owner only need to ride according to the cycling route displayed on the interface. After reaching the destination, the owner can determine the placement of the bicycle based on the time length of his business. The bicycle can be placed somewhere suitable to park on the destination and set coded lock at the same time, or it can be placed on the bicycle station outside the first-level parking lot nearest to the destination.

If the car owner places the bicycle on the bicycle station outside a first-level parking lot and plans to only use the function of querying bicycle of the system when he returns, the system will provide three nearest bicycle stations to the car owner and the number of available bicycles and guide the car owner to the bicycle station by navigation function, while the owner only need to ride back to the bicycle station outside the second-level parking lot where he parked, return the bicycle and drive back.

\subsection{Application of Temporary Bus Card.}

For those users who park their cars in the second-level parking lots but inconvenient to ride bicycle, the system provides a temporary bus card function for public transport transfer, and the users only need to click the temporary bus card function and recharge appropriate amount when booking second-level parking lots. The parking lot management system will handle temporary bus card for users. After the users enter the parking lots and the information like licenses plate numbers are scanned and verified, they can take the reserved temporary bus card on entrance. The difference between temporary bus card and traditional bus card is: the card binds the identity information of the user, and when the bus card is returned to the parking lot, the amount will be automatically returned to the user's payment account, and the identity binding will be canceled; the card can be recycled and the identity information can be timely added and canceled when the user books or returns; the card as a smart card has inherited the advantages of magnetic card and other IC cards and has extremely high security, confidentiality and anti-counterfeiting ability.

\subsection{Improvement and Innovation of Traditional Public Bicycle System.}

(1)Automatic detection device: collects the service condition of bicycles and send real-time feedback to the computer system of parking lots through the induction device which is installed on the bicycle frame.

(2)GPS offline navigation: after the bicycle is borrowed successfully, the LCD screen will automatically display the urban offline navigation system, so that the users can directly touch the screen or press the button at the bottom of the screen to complete the destination location. (Fig. 3) 


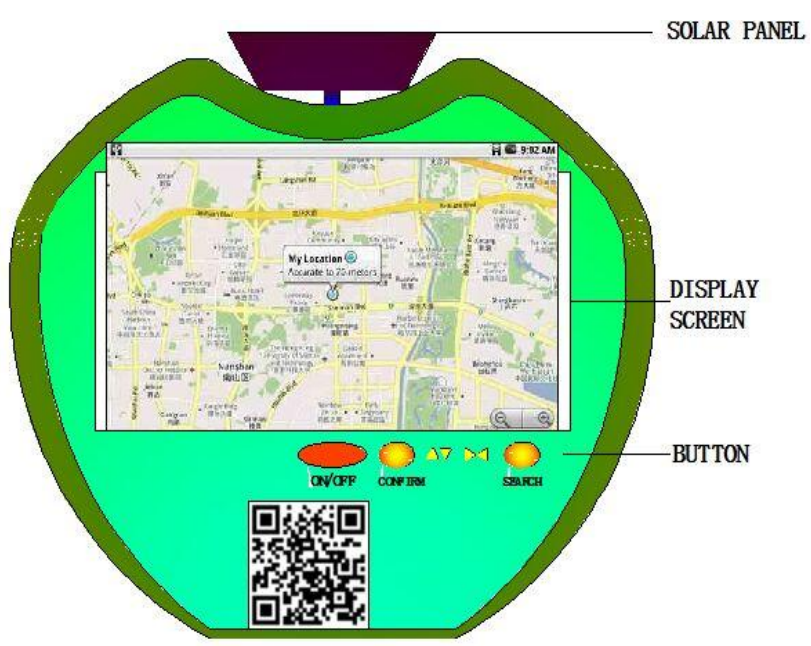

Fig. 3 Interface of bicycle navigation

(3) Two-dimensional code technology: people who want to borrow the bicycle can enter bicycle service interface to complete borrowing by swiping or card or using mobile phone to scan the two-dimensional code at the bottom of the LCD in the front of the bicycle.

(4) Smart car lock: on one hand, this car lock can ensure that there are enough available bicycle for the users after they arrive at the parking lot within booking time, on the other hand it meet the needs of users for temporary parking.

(5) Children's seat and storage rack: considering that the car owners may take a child with them sometimes, the bicycle system also has a bicycle with special children's seat. At the same time, to meet the shopping needs of users, the bicycle also has a bicycle basket.

(6) Bicycle placement point: each parking lot is equipped with a public bicycle station, and the specific number of bicycles set on each station shall be set according to the actual situation. This kind of bicycles is provided by the parking lot and the enterprise together, which is different from the existing public bicycles provided by the government.

\subsection{Input and Benefits of the Bicycle System.}

Input: the public bicycle system of this system has been improved and optimized and the cost needed has also large increased, so the bicycles equipped with parking lots shall be provided by the parking lot and the enterprise together.

Benefits: the number of running motor vehicles of parking lots will increase and the utilization of parking spaces will be improved, which will bring profits; the bicycle borrower swipe card or scan two-dimensional code to pay the borrowing cost (tentatively fixed as one yuan for each time); enterprise can use the bicycles to make advertisements, which will bring the unforeseen benefits.

\section{SOCIAL BENEFITS}

\subsection{Instance Analysis.}

In view of parking problems, this paper collects data results from about 1000 people with online survey method and gets the average required time for finding a parking space after reaching the busy shopping malls or scenic spots, as shown below(Fig.4):

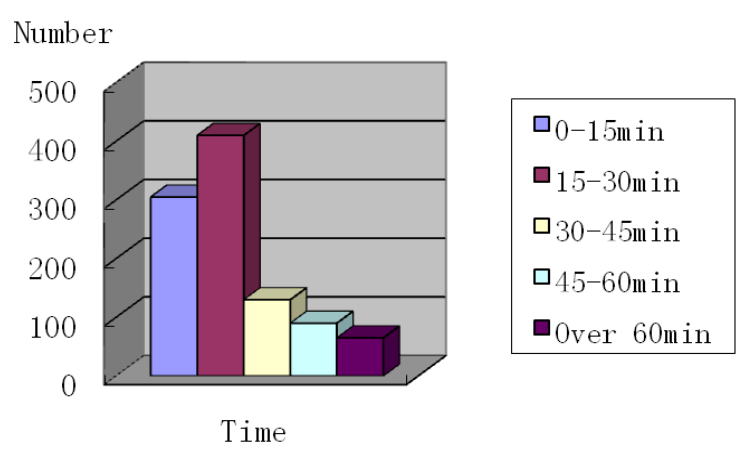

Fig.4 Time distribution chart for finding a parking space

According to the results of the survey, it can be known that for the downtown section or scenic spots, it takes about 30 minutes as average time to find parking space, however, after using the system, looking for a parking space is a process of using the terminal to book a parking space, taking about $5 \sim 10$ minutes.

\subsection{Alleviation Effects of Traffic Congestion after the \\ System Application.}

Assumptions on the scenic spot $\mathrm{A}$ on a particular time period:

The average traffic flow of scenic spot $\mathrm{A}$ is 10,000 vehicles; there are 5 first-level parking lots (within 1000 meters from A) near scenic spot A (the number of parking spaces are respectively $1400,300,400,500,800,3400$ in total), and 10 secondary parking lots (between $1000 \sim 3000$ meters); "a"is a main road leading to scenic spot $\mathrm{A}$.

Through analysis, it can be known that after the application of the system, the second-level parking lots can share some proportion of the number of vehicles, which can effectively alleviate the traffic pressure in scenic spot A. The original blocking time of "a": after access to information, the average daily blocking time is assumed to $3 \mathrm{~h}$ or more, and the proportion of second-level parking lots share is:

$1-\frac{\text { the number of parking spaces of first-level parking lot }}{\text { total vehicle flow }}=\left(1-\frac{3400}{10000}\right)=66 \%$ After the optimization of the system, the blocking time of " $a$ " can be reduced to $\mathrm{h}^{\prime}=\mathrm{h} \times 0.66=1.99 \mathrm{~h}$

\subsection{Specific to Unit Vehicles.}

Assuming that the distance between the car owner $\mathrm{A}$ and the scenic spot A is $20 \mathrm{~km}$, at the average speed of $40 \mathrm{~km} / \mathrm{h}$.

(1)Time-consuming without the use of the intelligent park and ride system: Known from the calculation, one consumes $0.5 \mathrm{~h}$ on road congestion time, about $0.4 \mathrm{~h}$ for looking for a parking space, and the road congestion time is $0.4 \mathrm{~h}$. After A parking his car, it will take him $0.3 \mathrm{~h}$ to walk to the entrance of scenic spot. The total time consuming is: $\mathrm{H}=0.5+0.4+0.4+0.3=1.6 \mathrm{~h}$.

(2)Time-consuming with the intelligent park and ride system:

A: If assigned by the system to a first-level parking lot " $\mathrm{K}$ " and the parking lot " $\mathrm{K}$ " is $0.5 \mathrm{~km}$ away from the scenic spot A, the car owner A spends $0.49 \mathrm{~h}$ on the road, congestion time $0.15 \mathrm{~h}$ (by equation 2 ), looking for parking time costing $0.1 \mathrm{~h}$, and after parking, A walks to the scenic spot A for about $0.13 \mathrm{~h}$. 
The total time consuming is: $\mathrm{H}=0.49+0.15+0.1+0.13=0.87 \mathrm{~h}$.

B: If assigned by the system to a second-level parking lot " $\mathrm{K}$ " and the parking lot $\mathrm{K}$ is $2 \mathrm{~km}$ away from the scenic spot $\mathrm{A}$, the car owner A spends $0.45 \mathrm{~h}$ on the road, congestion time $0 \mathrm{~h}$, looking for a parking space costing $0.1 \mathrm{~h}$, and after parking, ride a bicycle to the scenic spot $\mathrm{A}$, at the speed of about $12 \mathrm{~km} / \mathrm{h}$, consuming about $0.17 \mathrm{~h}$. The total time consuming is: $\mathrm{H}=0.45+0+0.1+0.17=0.72 \mathrm{~h} .($ Table I $)$

TABLE I: DATA ANALYSIS FIGURE

Without Assigned by the Assigned by the
assignment bysystem to asystem to a
the system,first-level parkingsecond-level parking

Data Analysis looking for thelot " $\mathrm{K}$ " and thelot " $\mathrm{K}$ " and the parking lot onparking lot " $\mathrm{K}$ " isparking lot $\mathrm{K}$ is $2 \mathrm{~km}$ their own $\quad 0.5 \mathrm{~km}$ away fromaway from the scenic the scenic spot A spot A

\begin{tabular}{lccc}
\hline $\begin{array}{l}\text { Time cost on } \\
\text { the road } \\
\text { Congestion }\end{array}$ & 0.5 & 0.49 & 0.45 \\
time & 0.4 & 0.15 & 0.1 \\
$\begin{array}{l}\text { Time cost to } \\
\text { look for a parking } \\
\text { space } \\
\begin{array}{l}\text { Walking time } \\
\text { Total time }\end{array}\end{array}$ & 0.4 & 0.1 & 0 \\
consuming & 1.6 & 0.13 & 0.17 \\
\hline
\end{tabular}

\section{InNOVATION ADVANTAGES OF THE SySTEM}

Linking networking, parking lot query and reservation system, and public bicycle system together, the system achieves effective transfer between private cars and bicycles, and thus relieving the "parking problems"; adding bicycle searching and booking system and booking temporary bus card function to the original system, the system increases the utilization of public bicycles and promotes the development of public transport; it realizes the parking lot grading (based on "one, three, five" travel) query and reservation data analysis, and increases the utilization of the parking spaces of non-downtown sections; setting and optimizing the GPS offline gravitation on the bicycles, and by the cooperative supply and profits of enterprises, it can reduce the government investment and result in a mutual benefit and win-win situation among enterprises, parking lot and city construction.

\section{REFERENCES}

[1] Wenbo Fan. Study on Analysis, Evaluation and Optimization of Park and Ride System. Master Thesis of Southwest Jiaotong University ,2009

[2] Jin Liu, LI Ming. "Study on New Ideas to Solve the Parking Problems -Taking Jiangsu Province as An Example". Collaborative Development and Practice of Traffic-- 2015 China's Urban Transport Planning conference and the 28th Symposium ,China,2015

[3] Yusan Zhang, JIAN Zihong, GUAN Youxi. "Study on Public Measures to Solve the 'Parking Problems' of the City." Journal of Liaoning Administration College Vol.22-24,2010,pp.22-24

[4] Qiaosong Cao, TANG Chong. "Study on Experience Reference and Countermeasure of Large Urban Curb Parking Both at Home and Abroad". Measures of Bus Priority and Alleviating Congestion-Symposium of China's 2012 Annual Urban Transport Planning Conference ,China,2012

[5] Yangwei Li, JIAO Pengpeng, DU Lin. Research on Urban Intelligent Parking Management System. Traffic Information and Safety ,2014

[6] Yongqing Huang. "Intelligent Parking Information Service System Based on the Internet of Vehicles". Artificial intelligence and identification technology, 2011
[7] Na Tan. Study on the Supply Mode of Urban Public Bicycle Service. (2013)

[8] Dong Zhou. "The Present Situation and Trend of Public Bicycle Development in China". Bicycles in China ,2010,ch.10,pp.52-55

[9] Tingting Li. Study on Location Planning of Urban Public Bicycle Rental Sites. Beijing Jiaotong University ,2010

[10] Junpeng. Yang Intelligent Parking Lot Service System Based on the Internet of Thing. Master Thesis of Zhongyuan University of Technology, 2014

[11] Li Jiang. Intelligent Parking Space Information Service System. Dalian University of Technology, 2011

[12] Chenguang Zhu. "Application of Intelligent Parking Lot Management System". The 27th China (Tianjin) Innovative Academic Seminar Theses on IT, Network, Information Technology, Electronics, Instrument in 2013,China,2013

[13] Jifei Yang. Design and Implementation of Intelligent Parking Payment System Based on the Internet of Things. Fudan University ,2010

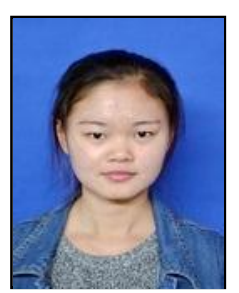

Yalin Liang was born on 15 June, 1994 in Jining, Shandong Province, PRC. Yalin Liang majors in traffic engineering and study in College of Transportation, Shandong University of Science and Technology, Qingdao City, Shandong Province, PRC.

She has published an article for The Transfer System of City Center Based on Intelligent Parking Service Platform, Beijing, China: Urban construction theory research, 2016. She is keen to study Intelligent Transportation recently.

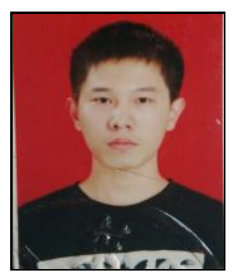

Chaoyang Zhang was born on 15 July, 1995 in Liaocheng, Shandong Province, PRC. Chaoyang Zhang majors in traffic engineering and study in College of Transportation, Shandong University of Science and Technology, Qingdao City, Shandong Province, PRC. He has published an article for Optimization of Transfer System, Beijing, China: Urban construction theory research, 2016. He recently researches on Urban Railway System.

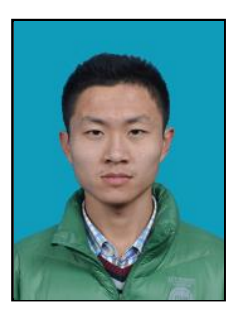

Su Gao was born on 13 July, 1995 in Liaocheng, Shandong Province, PRC. Su Gao majors in traffic engineering and study in College of Transportation, Shandong University of Science and Technology, Qingdao City, Shandong Province, PRC. He recently researches on Transportation planning and Management.

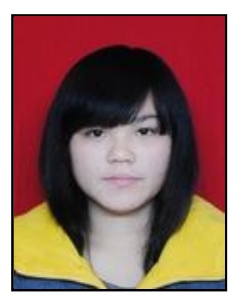

Shuangshuang Pang was born on 25 March, 1995 in Dezhou, Shandong Province, PRC. Shuangshuang Pang majors in traffic engineering and study in College of Transportation, Shandong University of Science and Technology, Qingdao City, Shandong Province, PRC.

She has published an article for The Transfer System of City Center Based on Intelligent Parking Service Platform, Beijing, China: Urban construction theory research, 2016. She is keen to study BRT recently.

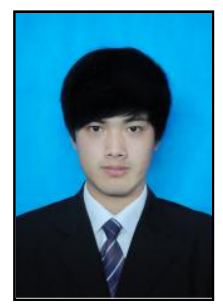

Zehua Du was born on 24 March, 1995 in Tangshan, Hebei Province, PRC. Zehua Du majors in traffic engineering and study in College of Transportation, Shandong University of Science and Technology, Qingdao City, Shandong Province, PRC.

He recently researches on Urban Railway System. 